\title{
The state of nutrition and the self-assessment of symptoms of depression in the group of seniors living in the countryside of Lublin province - preliminary report
}

\author{
Agnieszka Bartoszek, Renata Domżał-Drzewicka, Hanna Kachaniuk, Katarzyna Kocka, Katarzyna Muzyczka \\ Chair of Oncology and Environmental Health, Faculty of Nursing and Health Sciences, Medical University of Lublin, Lublin, \\ Poland
}

Key words: state of nutrition, depression symptoms, senior.

Address for correspondence: Renata Domżat-Drzewicka MD, PhD, Chair of Oncology and Environmental Health, Faculty of Nursing and Health Sciences, Medical University of Lublin, 4-6 Staszica St, 20-093 Lublin, Poland, phone: +48 605111 211, e-mail: renatadd@op.pl

\begin{abstract}
Introduction: The incidence of malnutrition increases together with the number of chronic diseases and medications taken daily. There are also other factors causing changes in the nutrition of the elderly, raising the risk of undernourishment. Such factors include difficulties with daily shopping, meal preparation and other everyday activities, hindering access to food with proper quantitative and qualitative properties. The nutritional state of the elderly is influenced not only by somatic disorders, but also by mental disorders such as depression.

Aim: To define the relationship between the nutritional state of the elderly living in their home environment and the incidence of depression.

Material and methods: The described sample consisted of 116 (100\%) elderly persons living in the Lubelskie Voivodeship, using the services carried out within primary healthcare. The nutritional state of the elderly was assessed with the use of the full version of the Mini Nutritional Assessment (MNA) questionnaire. In order to determine the intensity of depression symptoms, the Geriatric Depression Scale (GDS) (the 15-item version by Yesavage) was applied.

Results: During analysis of the impact of depression on malnutrition risk, a correlation with a high statistical significance level was found. Malnutrition was significantly more often identified in people in whom the GDS scale revealed severe depression $(p=0.00002)$. The risk of depression has a substantial impact on nutritional state. The nutritional state of the elderly deteriorates together with the increase of the risk of depression.

Conclusions: In over $48 \%$ of respondents, including those living with their families, an intensification of depression symptoms was found.
\end{abstract}

\section{Introduction}

In every period of human life, one's medical condition depends on use of nutrients present in one's ordinary diet. Therefore, the aim of evaluation of nutrition is the identification of individuals threatened with undernourishment or with being undernourished, determining the degree of undernourishment, and monitoring of effectiveness of any dietary treatment [1, 2].

Disorders of the state of nutrition depend on their intensification and are grouped, based on body mass index (BMI), into a few levels. These include states of excessive nutrition such as excess weight, obesity (level I, II, and III) - an oversupply of energy and low physical activity are the primary causes. States of deficiency include undernourishment (level I, II, and III) and are caused mainly by a chronic deficiency of energy and proteins [2].

The World Health Organisation (WHO) defines undernourishment (malnutrition) as "occurring on a cellular level, disequilibrium between the demand for nutrients and energy and the supply which permits the growth, support of bodily functions, and performance of specific functions" [1]. Therefore, we are talking about improper nutrition when the organism does not obtain 
a sufficient quantity of energy or lacking in essential nutrients, such as proteins, vitamins, minerals, or other nutrients needed to maintain correct homeostasis. This state may concern people of every age, with identified undernourishment, as well as overweight people and those presenting with obesity. Above all, the following groups of people are exposed to undernourishment: children, the elderly, those dependent on alcohol, drug users, expectant mothers and feeding mothers, individuals suffering from digestive problems, chronically ill patients, and hospitalised individuals [2].

In Europe, about 33 million people are exposed to the risk of undernourishment. Studies show that from this group, $10 \%$ are individuals over 65 years old. The frequency of undernourishment and the risk of undernourishment in elderly people remaining in the home environment is estimated at about 2-30\% [3-8].

The incidence of undernourishment increases along with the number of chronic diseases and medicines taken on a daily basis [9]. There are also other factors that influence changes in the dietary practices of elderly people, increasing their risk of undernourishment. These factors include problems in independent shopping, preparing meals and other activities of everyday life, limiting access to an appropriate diet in terms of the amount and the quality [10].

The state of nutrition of seniors, apart from somatic disorders, is strongly influenced by disturbances of the psychological sphere, i.e. depression [11]. Depression is the most commonly encountered mental disorder in patients above 65 years of age, which increases their mortality rate [12].

Advanced age is a common risk factor for the appearance of depression and of undernourishment, and of physiological changes in the process of growing old (worsening of vision and the sense of smell, reduction in the secretion of saliva and of pancreatic and hepatic enzymes), adverse socio-economic conditions (bad financial circumstances, social isolation, solitude, period of mourning), and medical ones, i.e. chronic illnesses and diseases, disability [4, 6, 12-15].

Depression is determined as the [16] set of emotional disorders (states of lowered, dispirited mood), often co-occurring with somatic diseases and/or their increasing manifestation.

It is estimated that in more than $15 \%$ of individuals over 65 years of age symptoms of depression occur that substantially hamper everyday functioning. Clinical symptoms of depression affecting the state of nutrition directly are the following: eating disorders, weight loss of a few up to approximately a dozen kilograms within a few months, lowering the psychomotor drive, the feeling of slowing down, tiredness, listlessness, sense of guilt, worthlessness, or hopelessness, and recurring thoughts about death or suicide. In older age a distinctive feature of depression is the appearance of 'masked depression'. This constitutes a serious diagnostic problem due to the fact that patients complain exclusively about somatic complaints. An important problem associated with depression [17] and undernourishment in older age is low detectability, in particular when the person is staying at home.

It has been taken as a norm that the home environment is the most advantageous environment for people's functioning, including the elderly, and the system of healthcare, mainly primary healthcare, is supposed to uphold this state.

\section{Aim}

Determining the frequency of the appearance of disorders in the state of nutrition and symptoms of depression and connections occurring between them in the group of elderly people living in the countryside in the home environment, being under the care of the primary health care therapeutic team was the purpose of the study.

The appropriate assessment of the aspects of health described above of the senior citizens allows an understanding of his/her needs and problems and facilitates preventive and/or therapeutic action of the primary health care team.

\section{Material and methods}

The study group consisted of 116 (100\%) elderly people (preliminary study) inhabiting the Lublin province, who were receiving benefits from primary health care. The choice of the group was intentional, and the participation in the research was voluntary, conditioned with agreement of the patient. The criteria for selection to the research group were: finished $65^{\text {th }}$ year of life, living in the country in the home environment, the preserved possibility of the logical contact, and the medical condition enabling research to be conducted with the help of standardised tools.

The research was conducted in 2013. An unabridged version of the Mini Nutritional Assessment Questionnaire (MNA) was used for the evaluation of the state of nutrition of elderly people containing anthropometric findings, evaluation of the quality of life, of dietary practices, and self-assessment of the examined medical condition. This is a simple screening test, recommended by a lot of institutions, for universal application for the risk assessment of undernourishment of patients above the $65^{\text {th }}$ year of age. It is applied in many hospitals around the world, and in the evaluation of the state of nutrition of elderly individuals, living in their own 
homes. Thanks to the MNA it is possible to diagnose early and quickly the appearance of the risk of undernourishment, and consequently, to implement appropriate dietary treatment. The desired complementation of this evaluation is an observation of dietary practices of the patient and his/her education to deal with the existing irregularities $[9,18]$.

The maximum number of points that the examined person can receive is 30 . A result of $\geq 24$ indicates sound nutrition, 17-23.5 points shows a risk of the undernourishment, and $<17$ points determines a state of undernourishment. Body mass index (BMI), being the element of MNA, was described based on anthropometric measurements: height $(\mathrm{cm})$ and body mass $(\mathrm{kg})$.

In order to detect increasing symptoms of depression, the Geriatric Depression Scale GDS (15-point version according to Yesavage) was used. GDS assesses the psychological frame of mind of the person examined within the 2 last weeks. In the research a 15-point abridgement was used. Every question in the test has two possible answers: yes or no. An examined person choosing the answer attesting to malaise receives one point. A result of $0-5$ is assessed as the state without symptoms of depression, 6-10 means moderate depression, and 11-15 means serious depression. In order to collect social-demographic data, an author's questionnaire of the questionnaire form was prepared.

\section{Statistical analysis}

The obtained research material was subjected to qualitative and statistical analysis using Statistica 10.0 software, applying the nonparametric $\chi^{2}$ test. For the border level of statistical significance a $p$ value was assumed as $\leq 0.05$.

\section{Results}

In the examined group of $116(100 \%)$ individuals there were 67 (57.8\%) women and 49 (42.2\%) men. In the period of the 'early old age' (65-74 years of life) there were $78(67.2 \%)$ individuals; the remaining $38(32.8 \%)$ were older. Individuals living in the countryside comprised the majority - 76 (65.5\%). A clear majority - 90 individuals (77.6\%) lived with their family, and $26(22.4 \%)$ by themselves. A large portion of the examined individuals described their financial circumstances as bad, describing it as 'the income is not enough for all needs' ( $n=78,67.2 \%)$. The majority of the examined declared the appearance of the at least one chronic disease, mainly cardiovascular diseases, diabetes, organopathies of the motor system, or nutritional problems.

After calculating the body mass index (BMI) value the state of being underweight was seen in 11 (9.5\%) individuals, correct body weight in 51 (44.0\%), excess weight in 36 (31\%), and obesity in 18 (15.5\%).

The correct state of nutrition concerned 65 (56\%) individuals, the risk of undernourishment was stated in $42(36.2 \%)$ individuals, and undernourishment in $9(7.8 \%)$ of the elderly people. Serious depression according to the GDS scale was stated for 23 (19.8\%) of the individuals, moderate for 33 (28.4\%), whereas $60(51.8 \%)$ individuals in the self-assessment of symptoms of depression were not declared at all (Table I).

In Table II the average values are described by the examined group in the scope of the assessment of the state of nutrition (MNA) and evaluations of depression (GDS).

In studying the link between the state of nutrition and the accepted variables, a relationship only between undernourishment and BMI values was shown. The risk of undernourishment most often concerned elderly people - 36 (70.6\%) with due body weight, whereas undernourishment concerned $8(72.7 \%)$ of the seniors with underweight ( $p<0.0001$; Table III).

The analysis was made concerning the influence of the appearance of symptoms of depression on the risk of undernourishment. An essential connection was stated at the highest level of statistical significance. Undernourishment has significantly more often concerned individuals for whom, based on self-assessment of their medical condition (GDS scale), the presence of symptoms of serious depression was stated ( $p=0.00002$; Table I).

\section{Discussion}

In Poland, studies devoted to the state of nutrition of seniors living in their home environment are scarce. The majority of research on this subject regards the incidence of this phenomenon in the hospital environment.

As can be seen from our own studies, over half of the examined presented a good state of nutrition, and the risk concerned with undernourishment affected just over $1 / 3$ of seniors living in the home environment. The studies of Wyka [19] state that in a group of 1001 individuals after the 60th year of age, living in their family house in Lower Silesia, 6.3\% had risk of undernourishment. In this group greater participation was stated regarding those over 75 years of age, living in the countryside, having primary education, independently performing activities like shopping. According to Strugała i Wieczorkowska-Tobis [15], and in our own research, a relation between the state of nutrition and socio-demographic factors was not stated.

Also in the research of WOBASZ-SENIOR concerning 1013 Polish residents over 75 years of age, a bad 
Table I. The assessment of the surveyed people's nutritional state and the presence of depression symptoms

\begin{tabular}{|c|c|c|c|c|c|c|}
\hline Parameter & & Severe depression & Moderate depression & Normal score & $\chi^{2}$ & Value of $p$ \\
\hline \multirow[t]{2}{*}{ Malnutrition } & $n$ & 6 & 2 & 1 & 27.46016 & 0.00002 \\
\hline & $\%$ & 66.7 & 22.2 & 11.1 & & \\
\hline \multirow[t]{2}{*}{ Malnutrition risk } & $n$ & 13 & 14 & 15 & & \\
\hline & $\%$ & 31.0 & 33.3 & 35.7 & & \\
\hline \multirow{2}{*}{$\begin{array}{l}\text { Proper nutritional } \\
\text { state }\end{array}$} & $n$ & 4 & 17 & 44 & & \\
\hline & $\%$ & 6.2 & 26.2 & 67.7 & & \\
\hline
\end{tabular}

$\chi^{2}$ - the Chi-square test, $p$-significance level.

Table II. The average values obtained by the surveyed in the nutrition (MNA) and depression (GDS) assessment

\begin{tabular}{lccccc} 
& \multicolumn{5}{c}{ Descriptive statistics } \\
\cline { 2 - 6 } & No. of valid $\boldsymbol{N}$ & Average & Minimum & Maximum & SD \\
\hline MNA & 116 & 23.15517 & 8.500000 & 29.00000 & 4.242853 \\
\hline GDS & 116 & 9.87069 & 1.000000 & 61.00000 & 6.293586
\end{tabular}

and poor degree of nutrition appeared in about $1 / 3$ of individuals in the period of late old age (30\% of men and $40 \%$ of women) [20]. The information that points to the correlation between undernourishment and low BMI indicator has appeared in the literature [21]. The authors of this study stated such a relation in the researched material ( $p<0.00001$, Table II). For as many as $72.7 \%$ of the examined undernourished, the BMI indicator pointed to the state of underweight. These results are close to those published by de Morais et al., Cereda et al., and Koo et al., where the low indicator of nutrition concerned individuals with low BMI below $19 \mathrm{~kg} / \mathrm{m}^{2}$ [22-24].

In elderly people, the BMI credibility is lower and results from problems in the evaluation of the height and the thorough determination of body weight, and the data from the self-assessment are burdened with large errors. In such a situation it is possible to estimate the body weight of elderly people in a lying position, based on indirect measurements, using the patterns for standing models developed by Chumlea $[25,26]$. The obtained findings only partly match the available results in the literature for individuals living in the home environment. The differences result from the complexity of research models and various parameters taken into account in individual analyses.

Undernourishment and the risk of undernourishment are most often stated amongst elderly people living in care institutions, and therefore the majority of research proves the significant influence of the domicile on the state of nourishment. Méndez Estévez in a multifactorial analysis on a group of 311 individuals confirmed the existence of the connection of undernour- ishment with staying in a care institution, with more advanced age - above 75 years of life, and with a greater number of diseases [13]. Humańska and KędzioraKornatowska reported [27] that individuals who lived with the family were characterised by statistically better nutrition than residents in care centres $(p=0.0002)$. The mean of the obtained points in the MNA scale for individuals living with the family was $24.28 \pm 2.42$ and was higher than in those living in care centres. The improved nutrition of seniors living with the family may result from consuming meals together with the family.

Elderly persons can participate in the preparation of meals and do not have to do the shopping; however, in the care centre the residents eat meals in the canteen with other individuals and lack the feeling of intimacy, especially when having difficulty with the self-service [28]. These results are very similar to those of Donini et al. and those of Morone et al. [5, 28]. Undernourishment is associated with numerous geriatric syndromes (depression, torpor, functional dependence, and coexisting diseases) having a significant influence on the subjective quality assessment of living in older age [29-34]. A great deal of research confirms the total influence of the existence of the relation of physical factors (mobility, cognitive disorders) and psychosocial ones (depression, sense of self-efficiency, attitudes towards health) on the risk of undernourishment among elderly people living at home [14, 35], as well as to all of these factors individually.

The causality between the state of nutrition and the appearance of symptoms of depressions is ambiguous because we do not have explicit evidence whether the undernourishment actually stands behind the depres- 
Table III. The evaluation of the state of nutrition of elderly people and the accepted variables

\begin{tabular}{|c|c|c|c|c|c|c|c|c|c|}
\hline \multirow[t]{2}{*}{ Parameter } & & \multicolumn{2}{|c|}{ Malnutrition } & \multicolumn{2}{|c|}{ Malnutrition risk } & \multicolumn{2}{|c|}{$\begin{array}{c}\text { Proper nutritional } \\
\text { state }\end{array}$} & \multirow[t]{2}{*}{$\chi^{2}$} & \multirow[t]{2}{*}{ Value of $p$} \\
\hline & & $n$ & $\%$ & $n$ & $\%$ & $n$ & $\%$ & & \\
\hline \multirow[t]{2}{*}{ Gender } & Women & 5 & 7.5 & 28 & 41.8 & 34 & 50.8 & \multirow[t]{2}{*}{2.1755} & \multirow[t]{2}{*}{0.33244} \\
\hline & Men & 4 & 8.2 & 14 & 28.6 & 31 & 63.3 & & \\
\hline \multirow[t]{2}{*}{ Age [years] } & $65-74$ & 4 & 5.1 & 28 & 35.9 & 46 & 59.0 & \multirow[t]{2}{*}{2.496963} & \multirow[t]{2}{*}{0.28694} \\
\hline & $\geq 75$ & 5 & 13.2 & 14 & 36.8 & 19 & 50.0 & & \\
\hline \multirow{2}{*}{$\begin{array}{l}\text { Place of } \\
\text { residence }\end{array}$} & Rural areas & 6 & 7.9 & 26 & 34.2 & 44 & 57.9 & \multirow[t]{2}{*}{0.3839830} & \multirow[t]{2}{*}{0.82531} \\
\hline & Urban areas & 3 & 7.5 & 16 & 40.0 & 21 & 52.5 & & \\
\hline \multirow{2}{*}{$\begin{array}{l}\text { Family } \\
\text { situation }\end{array}$} & Living alone & 2 & 7.7 & 13 & 50.0 & 11 & 42.3 & \multirow[t]{2}{*}{2.887900} & \multirow[t]{2}{*}{0.23600} \\
\hline & Living with family & 7 & 7.8 & 29 & 32.2 & 54 & 60.0 & & \\
\hline \multirow{4}{*}{$\begin{array}{l}\text { Body mass } \\
\text { index }\end{array}$} & Underweight & 8 & 72.7 & 3 & 27.3 & 0 & 0.0 & \multirow[t]{4}{*}{125.3439} & \multirow[t]{4}{*}{$<0.00001$} \\
\hline & Normal & 1 & 2.0 & 36 & 70.6 & 14 & 27.5 & & \\
\hline & Overweight & 0 & 0.0 & 3 & 8.3 & 33 & 91.7 & & \\
\hline & Obesity & 0 & 0.0 & 0 & 0.0 & 18 & 100.0 & & \\
\hline
\end{tabular}

$\chi^{2}$ - the Chi-square test, $p$-significance level.

sion, or whether perhaps the state of nutrition leads to depressive disorders [36]. The view that depression predisposes elderly people to undernourishment is universally accepted. At geriatric age, a characteristic feature is the appearance of hidden depression, constituting the biggest diagnostic problem as patients complain exclusively about somatic complaints: muscular - skeletal pains, worsening of locomotive abilities, sleeplessness, discomfort on the part of the digestive system, appetite disorders, headaches, feeling of permanent tiredness.

The majority of research emphasises the existence of a strong relation between depression and undernourishment, which is also noticeable in the findings of our own research. Along with the risk of the development of depression the risk of undernourishment grows - as many as $66.7 \%$ of the examined living at home who were undernourished had serious depression. These results are very similar to those of Mokhber and Majdi, Cabrera et al., and Ahmadi et al. Also, Koo et al. pointed out the existence of the connection between undernourishment and depression with the period of the advanced years ( $>75$ years of age), which was not confirmed in the research by Yoshimura et al. [24, 33-36].

In the newest and largest Norwegian research population study of 1558 men and 1553 women at geriatric age, living at home, manifestations of mental health problems strongly involved a certain amount of risk of undernourishment, and more often concerned women than men [37]. However, in the research of 579 Swedish seniors such a relation concerned more men than women [38].

In research published in 2011 Engel et al. [39] demonstrated that depression and general psychological malaise, disregarding age and the presence of chronic diseases, was connected with the poor appetite, and consequently, also with the risk of undernourishment. Kaburagi et al. as well as Cabrera et al. [35, 40] made similar observations in their research, the result of which, in the GDS scale, pointed to the presence of depression having the strongest impact on the state of nutrition.

In ESPEN (the European Society for Clinical Nutrition and Metabolism) recommendations it is emphasised that the aim of the dietary treatment of individuals in old age - besides delivering energy, protein, microelements, and the improvement or the maintenance of the state of nutrition - is also improvement in efficiency, activity, and rehabilitation potential, the improvement or keeping the quality of life, and the improvement in prognosis (reducing morbidity and mortality) [41-44].

Prevention of nutrition disorders and the identification of symptoms of depression in the group of seniors is possible by applying the global geriatric assessment (GGA) by the primary health care team, including the doctor, nurse, and the midwife. The GGA is a multidirectional, interdisciplinary, integrated diagnostic process, the scope of which is establishing health problems, healing-rehabilitation priorities, the needs and possibilities of ensuring further treatment, nursing, rehabilitation, and overall care. Global geriatric assessment gives the chance of detecting invisible problems in the traditional, medical bedside manner in advanced age. Global geriatric assessment as a multidirectional diagnostic investigation determines the needs in care, and the required help, now and in the future. Planning the treatment, the nursing, and the care is a process of di- 
agnosing and qualifying the determined medical procedures and benefits [45]. So, improvement in the welfare of the senior is possible in Poland through preparing and implementing the strategy of the nursing care, the development of environmental psychiatry and stomatological care, as well as standardising geriatric care and the development of geriatric education.

\section{Conclusions}

Irregularities in the state of nutrition were stated at the $37.9 \%(n=44)$ of the examined individuals, whereas in over $48 \%(n=55)$ of individuals, living with the family and increasing symptoms of depression were stated. The appearance in the subjective evaluation of symptoms of depression significantly affects the state of nutrition. Along with the increase in the risk of depression, the state of nutrition of the elderly people of the examined group is deteriorating. A relation between the state of nutrition and the value of the BMI exists. The risk of undernourishment most often concerns elderly people with due body weight, whereas undernourishment affects seniors who are underweight. The remaining variables did not diversify the class of nutrition statistically examined. The collected data indicated the need for intervention by the primary health care team in almost a half of the examined people.

Further research on the connection between the state of nutrition of seniors living in the home environment and the increasing symptoms of depression is necessary [44] to influence the improvement of the quality of their life, refund politics, to prevent the process of institutionalisation, to identify and to eliminate risk factors, and to show the need and to develop standards of team work (education of medical staff) in the care of seniors at different levels of the system of health care, including the level of primary health care. Reduction of undernourishment and the early detection of depression in the group of people over 65 years of age will influence the reduction of costs of the health care directly in the longer term and will contribute to the improvement of the quality of their life.

\section{Conflict of interest}

The authors declare no conflict of interest.

\section{References}

1. World Health Organization; UNICEF; UN System Standing Committee on Nutrition (2006). WHO, UNICEF, and SCN informal consultation on community-based management of severe malnutrition in children - SCN Nutrition Policy Paper No. 21. http://www.who.int/child_adolescent_health/documents/ fnb_v27n3 suppl/en/index.html (access 16.06.2014).
2. http://polspen.pl/kursy/materialy-szkoleniowe/bydgoszcz-22-ix-2012/definicja-niedozywienia-wg-espen.pdf (access 16.12.2014).

3. Ljungqvist O, de Man F. Undernutrition - a major health problem in Europe. Nutr Hosp 2009; 24: 368-70.

4. Serrano-Urrea R, Garcia-Meseguer MJ. Malnutrition in an elderly population without cognitive impairment living in nursing homes in Spain: study of prevalence using the Mini Nutritional Assessment test. Gerontol Pol 2013; 59: 490-8.

5. Morrone A, Donini LM, Scardella P, et al. Malnutrition in the elderly: clinical features, psychological and social determinants. Preliminary results. Ann Ig 2011; 23: 161-72.

6. Skokowska B, Dyk D, Miechowicz I. Implementation of caloric intake among ill elderly people [Polish]. Now Lek 2013; 82: 108-11.

7. Biernat J, Wyka J. Nutrition status and health status [Polish]. Now Lek 2011; 80: 209-12.

8. Jarosz M, Kłosiewicz-Latoszek L, Charzewska J, Białkowska M. Diagnosing problems nutritional status and clinical practice of nursing [Polish]. Wyd Instytut Żywności i Żywienia, Warsaw 2010; 9: 19-23.

9. Wojszel B. Malnutrition and nutritional therapy dilemmas in geriatrics [Polish]. Post Nauk Med 2011; 24: 649-57.

10. Rodríguez-Tadeo A, Wall-Medrano A, Gaytan-Vidaña ME, et al. Malnutrition risk factors among the elderly from the US-Mexico border: the "one thousand" study. J Nutr Health Aging 2012; 16: 426-31.

11. Puto G, Ocetkiewicz T, Zawisza K. Influence of depression and cognitive function on subjective assessment of quality of life in patients over 80 years old with myocardial ischemia [Polish]. Gerontol Pol 2007; 15: 90-6.

12. Lechleitner M, Hoppichler F. Gender aspects of malnutrition and associated sequelae. Prevention and therapy. Gerontol Geriatr 2013; 46: 511-6.

13. Méndez Estévez E, Romero Pita J, Fernández Domínguez MJ, et al. Do our elderly have an adequate nutritional status? Nutr Hosp 2013; 28: 903-13.

14. lizaka S, Tadaka E, Sanada H. Comprehensive assessment of nutritional status and associated factors in the healthy, community-dwelling elderly. Geriatr Gerontol Int 2008; 8: 24-31.

15. Strugała M, Wieczorkowska-Tobis K. The assessment of the nutritional status of patients at the Geriatric Ward in the context of their functional status [Polish]. Geriatria 2011; 5: 89-93.

16. Wciorka J. Quick reference to the diagnostic criteria from DSMIV-TR [Polish]. Wydawnictwo Urban \& Partner, Wrocław 2008.

17. Albiński R, Kleszczewska-Albińska A, Bedyńska S. Geriatric Depression Scale (GDS). Validity and reliability of different versions of the scale - review. Psychiatr Pol 2011; 45: 555-62.

18. Krzymińska-Siemaszko R, Wieczorowska-Tobis K. Evolution of the malnutrition assessment in older patients by means Mini Nutritional Assessment [Polish]. Geriatria 2012; 6: 139-43.

19. Wyka J. Nutritional status of people over 60 years of age in terms of conditions of food, health, environmental and socio-demographic [Polish]. Wyd. Uniwersytetu Przyrodniczego we Wrocławiu, Wrocław 2009.

20. Waśkiewicz A, Sygnowska E, Broda G. Evaluation of health and nutritional status of persons aged $75+$ in Polish population 
Wobasz-senior project [Polish]. Bromat Chem Toksykol 2012; 3: 614-8.

21. Tojek K, Frasz J, Szewczyk MT, et al. Assessment of the state of nutrition of patients hospitalized in the Department of General Surgery on the basis of NRS 2002 form [Polish]. Pielęgniarstwo Chirurgiczne i Angiologiczne 2009; 4: 144-50.

22. de Morais C, Oliveira B, Afonso C, et al. Nutritional risk of European elderly. Eur J Clin Nutr 2013; 67: 1215-9.

23. Cereda E, Valzolgher L, Pedrolli C. Mini nutritional assessment is a good predictor of functional status in institutionalised elderly at risk of malnutrition. Clin Nutr 2008; 27: 700-5.

24. Koo YX, Kang ML, Auyong A, et al. Malnutrition in older adults on financial assistance in an urban Asian country: a mixed methods study. Public Health Nutr 2013; 6: 1-10.

25. Barceló M, Torres O, Mascaró J, et al. Assessing nutritional status in the elderly evaluation of Chumlea equations for weight. Nutr Hosp 2013; 28: 314-8.

26. Principles of good nutrition of patients in hospitals [Polish]. Jarosz M (ed.). Instytut Żywności i Żywienia, Warsaw 2011.

27. Humańska M, Kędziora-Kornatowska A. Influence of place of residence on nutrition in the elderly [Polish]. Gerontol Pol 2009, 17: 126-8.

28. Donini LM, Scardella P, Piombo L, et al. Malnutrition in elderly: social and economic determinants. J Nutr Health Aging 2013; 17: 9-15.

29. Kane RL, Shamliyan T, Talley K, Pacala J. The association between geriatric syndromes and survival. J Am Geriatr Soc 2012; 60: 896-904.

30. Agarwal E, Miller M, Yaxley A, Isenring E. Malnutrition in the elderly: a narrative review. Maturitas 2013; 76: 296-302.

31. Rasheed S, Woods RT. Malnutrition and quality of life in older people: a systematic review and meta-analysis. Ageing Res Rev 2013; 12: 561-6.

32. Saka B, Kaya O, Ozturk GB, et al. Malnutrition in the elderly and its relationship with rother geriatric syndromes. Clin Nutr 2010; 29: 745-8.

33. Ahmadi SM, Mohammadi MR, Mostafavi SA, et al. Dependence of the geriatric depression on nutritional status and anthropometric indices in elderly population. Iran J Psychiatry 2013; 8: 92-6.

34. Mokhber N, Majdi MR. Association between malnutrition and depression in elderly people in Razavi Khorasan: a population based-study in Iran. Iran J Public Health 2011; 40: 67-74.

35. Cabrera MA, Mesas AE, Garcia AR, de Andrade SM. Malnutrition and depression among community-dwelling elderly people. J Am Med Dir Assoc 2007; 8: 582-4.

36. Yoshimura K, Yamada M, Kajiwara Y, et al. Relationship between depression and risk of malnutrition among community-dwelling young-old and old-old elderly people. Aging Ment Health 2013; 17: 456-60.

37. Kvamme JM, Grønli O, Florholmen J, Jacobsen BK. Risk of malnutrition is associated with mental health symptoms in community living elderly men and women: the Troms $\varnothing$ study. BMC Psychiatry 2011; 17: 112.

38. Johansson Y, Bachrach-Lindström M, Carstensen J, Ek AC. Malnutrition in a home-living older population: prevalence, incidence and risk factors. A prospective study. J Clin Nurs 2009; 18: 1354-64.
39. Engel JH, Siewerdt F, Jackson R, et al. Evaluation of weight loss in the community-dwelling elderly with dementia as assessed by eating behavior and mental status. J Am Geriatr Soc 2011; 59: 482-7.

40. Kaburagi T, Hirasawa R, Yoshino $\mathrm{H}$, et al. Nutritional status is strongly correlated with grip strength and depression in community-living elderly Japanese. Public Health Nutr 2011; 14: 1893-9.

41. Sobotka L, Schneider SM, Berner YN, et al. ESPEN guidelines on parenteral nutrition: Geriatrics. Clin Nutr 2009; 28: 461-6.

42. Phillips RM. Nutrition and depression in the community-based oldest-old. Home Health Nurse 2012; 30: 462-77.

43. Scardella P, Piombo L, Neri B, et al. Malnutrition in elderly: social and economic determinants. J Nutr Health Aging 2013; 17: 9-15.

44. Łopuszańska M, Szklarska A, Jankowska AE. Assessment of severity of depressive symptoms using the Polish version IA of Beck Depression Inventory in healthy men, inhabitants of Wrocław [Polish]. Psychiatr Pol 2013; 47: 1001-9.

45. http://www.mz.gov.pl/zdrowie-i-profilaktyka/opieka-nad-osobami-starszymi (access 16.12.2014).

Received: 17.12 .2014

Accepted: 7.01.2015 